\title{
CORTISONE AND ACTH ${ }^{*}$
}

\author{
By Oswald Savage, O.B.E., M.R.C.P. \\ Physician, Arthur Stanley Institute, The Middlesex Hospital; Assistant Physician, Rheumatism Department, \\ West London Hospital
}

An increasing number of papers is being published on the application of cortisone and ACTH in various fields of medicine. Most of the work is being done in America where they are available, but the results of small-scale studies which have been done in Europe are appearing. The general picture of possible therapeutic usefulness is beginning to emerge, though the original workers, Hench, Kendall, Slocumb and Polley, have not yet used the word treatment in their publications from the Mayo Clinic.

It is now obvious that every physician will have to know something of the action and the results of overdosage with cortisone and ACTH, because these drugs may come to have a place in the treatment of a wide variety of conditions which, up to date, have been considered of different aetiology.

Much of the early work has been done in the field of the rheumatic diseases, and it appears that this is likely to be the main place for their use in treatment, but there seems no doubt that they will have a usefulness in many other conditions.

\section{History}

In 1855 Thomas Addison described the syndrome, which bears his name, in a manner which has become a classic of clinical observation. $\mathrm{He}$ attributed a life-maintaining function to the adrenal cortex. The next year Brown-Sequard (1856) performed the first experimental adrenalectomies and verified the hypothesis that the adrenals were essential to life, though his conclusions were challenged by other workers. During the remainder of the Igth century only sporadic work was done, but it was gradually agreed that Addison and Brown-Sequard were right and that the apparent exceptions were due to varying amounts of accessory adrenal tissue. An additional two decades were spent on the question of whether it was the adrenal cortex or medulla that was essential, a controversy which arose because of the discovery of epinephrine about 1900, which diverted attention from other possible secretions.

In the 1900's there was an era of study of adrenal

* Based on a lecture given in the Empire Rheumatism Council's autumn course, November, 1950. physiology, and in 1924 Stewart wrote 'The cortex is the part of the adrenal essential to life. How it exercises its function is utterly unknown.' Six years later Britton concluded "That the very meagre knowledge of cortical function does not lend itself at the present time to even rational theorizing.'

The difficulties of studying adrenal physiology were in a large part due to inexpert animal surgery, which usually resulted in such quick death after adrenalectomy that only animals in a state of acute collapse were available for experimental study. Stewart (1924) emphasized the need for a high standard of surgical technique and demonstrated that adrenalectomized dogs could live for periods of ten days, and so sound physiological studies could be undertaken.

It was found that blood chlorides decrease after adrenalectomy as did plasma $\mathrm{Na}, \mathrm{pH}$ and bicarbonate, while total solids, $\mathrm{K}$ and $\mathrm{Mg}$, rose. The administration of Ringer's solution was found to be beneficial to adrenalectomized animals in which a low blood sugar and relative enlargement of the lymphatic tissues were noted.

None of this work however was such as to permit a convincing statement of the function of the adrenal cortex, and it was not until r930 that the modern history of the adrenal was opened when the preparation of the first good cortical extracts was announced.

It is generally agreed that Swingle and Pfiffner and Hartman, Brownell and others were the first to describe methods based on lipoid extraction procedures which produced extracts that would keep adrenalectomized animals and Addisonian patients alive indefinitely.

In I 936 work from the laboratories of Pfiffner, -Reichstein and Kendall began to show that a large number of steroids could be crystallized from cortical extract. The early adrenal extracts caused suppression of pituitary adrenocorticotrophic hormone in patients with normal adrenal glands, and it was not until the isolation of ACTH by $\mathrm{Li}$, Evans and Simpson, and by Sayers, White and Long in 1943, and the synthesis of cortisone by Sarett in 1946 that the clinical potentialities of these substances could be studied. 
GROL; I

I 7-Hydroxy-I I-dehydrocorticosterone

(Compound E)

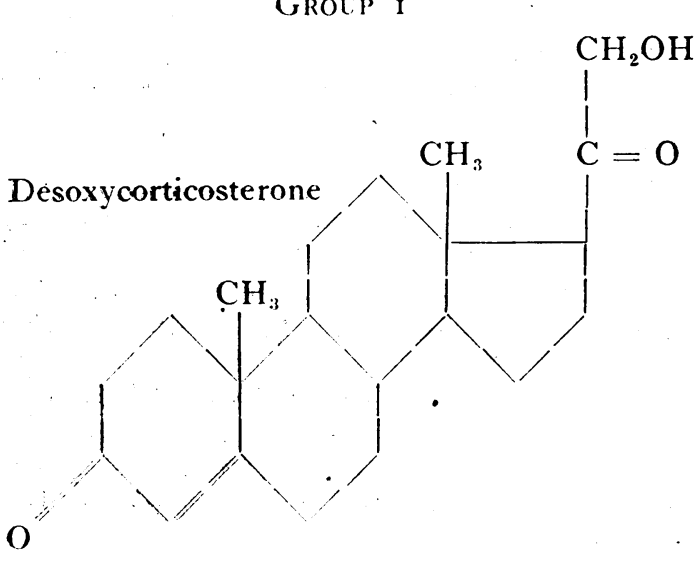

Group 2

Corticosterone (Compound $\mathrm{B}$ )

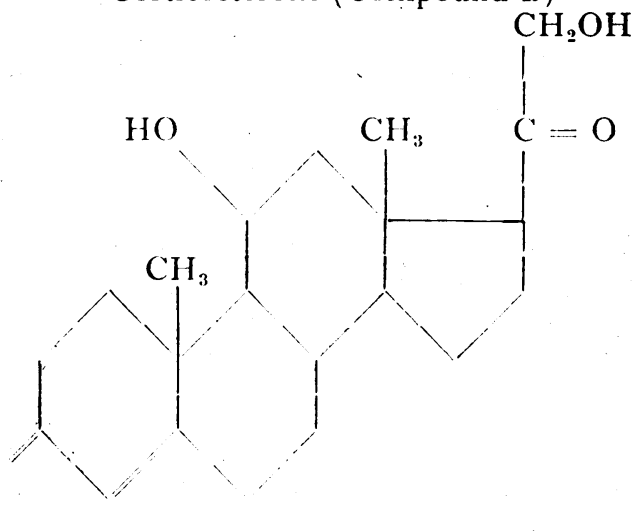

Dehydrocorticosterone (Compound A)

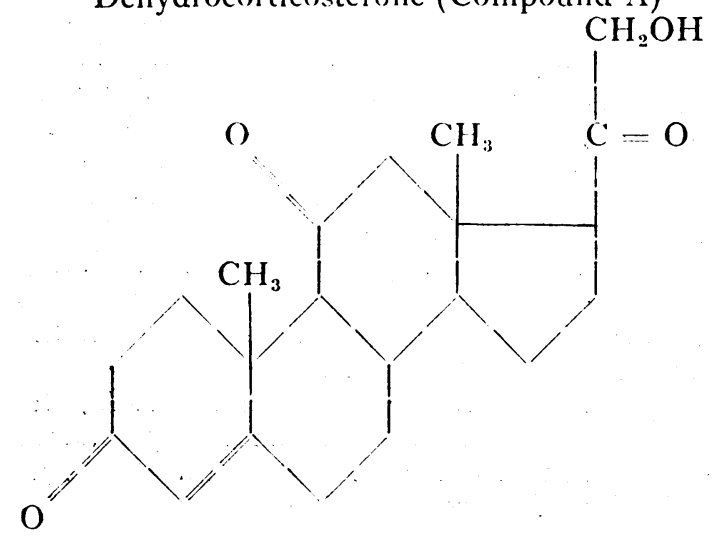

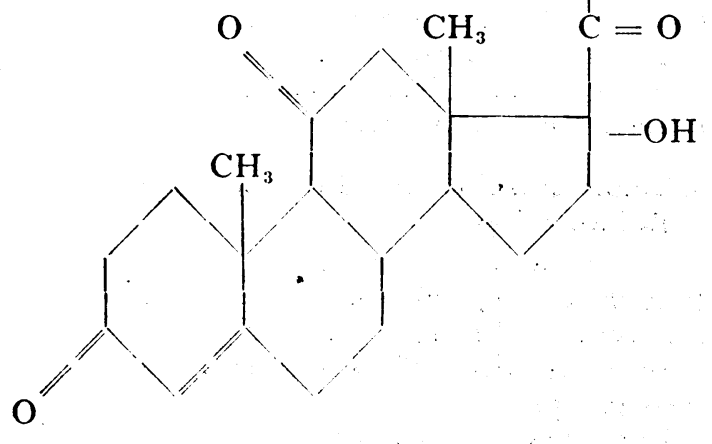

I7-Hydroxycorticosterone

(Compound F)

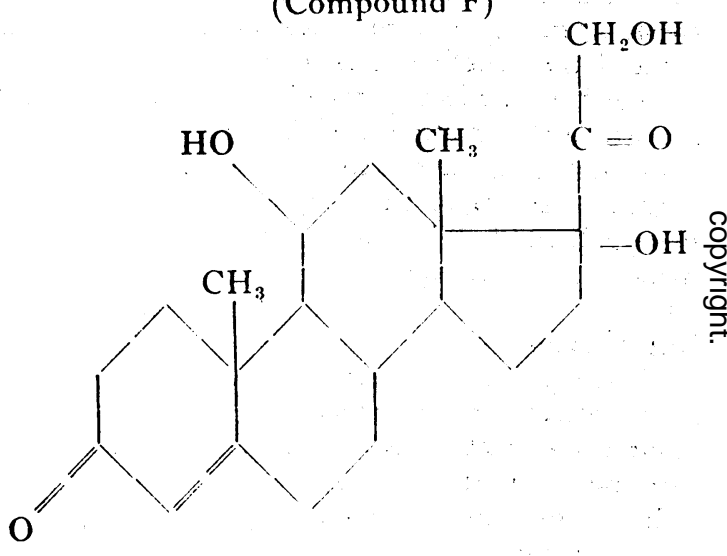

Group 3

I7-Hydroxy-I I-desoxycorticosterone

(Compound S)

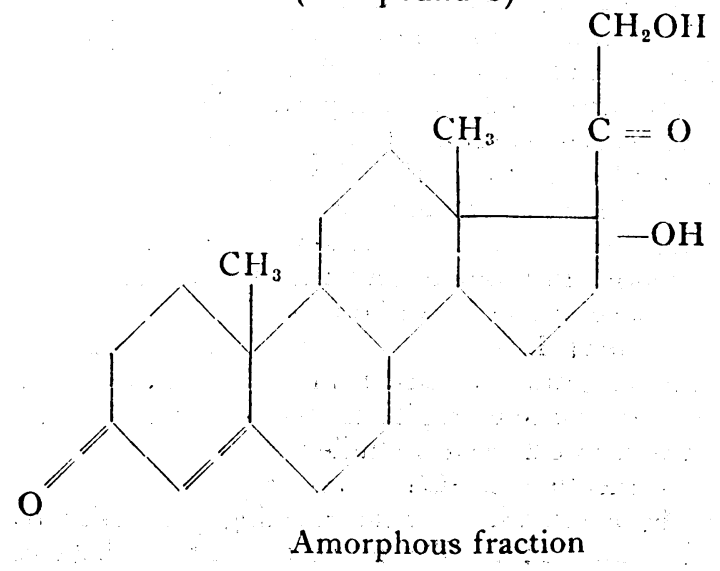


In 1949 Hench and his associates described the remarkable effects of cortisone and ACTH in rheumatoid arthritis and of cortisone in rheumatic fever. These results were soon substantiated, notably by Freyberg and by Boland. Since then the field of investigation has widened to many conditions. In $195^{\circ}$ Hench, Kendall and Reichstein were awarded the Nobel prize in medicine for their work in this field.

\section{Adrenal Steroids and Pituitary Adrenal Relationship}

So far 28 adrenal steroids have been isolated from the cortex; only six are known to have corticoid activity, although some of the others have sex hormone activity. These six can be divided into three groups.

In the first is desoxycorticosterone alone. This substance and its acetate DOCA have been studied for longer periods than the others, as in 1937 Steiger and Reichstein announced its cheap synthesis from stigmasterol. Although there is now some doubt whether it is a true adrenal steroid, DOCA has an effect on the electrolyte balance and is used in the treatment of Addison's disease.

Group 2 contains the II-oxysteroids, compounds A and B, and the II, I7-oxysteroids, compounds $E$ and $F$. These act mainly on carbohydrate metabolism and also have an effect on the lymphoid tissue as shown by a fall in eosinophils and lymphocytes.

Group 3 contains compound S, which has its main effect on electrolyte balance, and the amorphous fraction which, though known to be extremely potent, is relatively unstudied.

It is becoming increasingly clear that the structural formula of cortisone is in some curious way specific in all its details. Since the discovery of its dramatic action in rheumatoid arthritis a large number of other steroids have been tried for anti-rheumatic effect.

Copeman, et al. (1950) have tested a number in this country, and Polley and Mason (1950) at the Mayo Clinic have shown that compounds $A$ and $B$ are without effect. Compound $F$ is active but is still extremely difficult to produce, and adrenal cortical extract capsules, though effective, require a prohibitive amount of hog adrenal tissue. Altogether an immense amount of work has been expended in trying to find a cheaper substitute for cortisone but so far without result.

In 1924 Evans noted that certain extracts of anterior pituitary caused adrenal hypertrophy in rats, and since then pituitary-adrenal relationships have been extensively studied.

As mentioned, ACTH was prepared and shown to have remarkable heat resisting properties by $\mathrm{Li}$, et al. (1943). The properties of the substance have been admirably presented by Henly (r949). Dougherty and White (1943) showed that ACTH increased the production of II-oxysteroids and so worked through the adrenals. $\mathrm{Li}$ (1949) reported the isolation of a peptide more powerful than the original protein, which gave hope of future synthesis.

It is considered that the production of $\mathrm{AC}$ 'TH is controlled from the higher centres, and recently Harris and de Groot (1950) have put forward evidence that it is under neural control via the hypothalamus and hypophysial portal vessels. The relationship between the adrenal and pituitary is unquestionably a mutually interdependent one, for destruction of the anterior hypophysis results in adrenal cortical atrophy, while adrenal cortical disease induces morphological changes in the pituitary.

\section{Metabolic and Hormonal Effects}

Cortisone exerts a profound effect on carbohydrate metabolism. It increases gluconeogenesis with increased deposition of glycogen in the liver. Large doses may produce hyperglycaemia with glycosuria and increased resistance to insulin.

ACTH also acts on sugar metabolism independently as well as through the adrenal cortex. Protein metabolism is effected to a small degree and the ability of cortical extract to increase liver glycogen in the fasting and adrenalectomize animal without affecting muscle glycogen suggests that the added glycogen must come from some other source, probably protein. On large doses of cortisone there is increased excretion of nitrogen with a negative protein balance.

Uric acid excretion in the urine is raised by cortisone and ACTH and is thought to be due to an effect on the renal tubules with a change in the renal clearance.

Although the adrenal hormones having the main effect on electrolyte balance are the mineralocorticoids such as DOCA and compound S, cortisone and ACTH produce changes which are important in long-term treatment. The excretion of potassium is increased and hypokalaemia has been seen with weakness, hypotension and characteristic changes in the electrocardiogram, such as lowering of the $\mathrm{T}$ waves. Sprague, et al. (I950), who have done extensive metabolic studies at the Mayo Clinic, conclude that a sufficient amount of potassium appears in the urine during continued administration of these hormones to indicate that it may be derived from both the extracellular and the intracellular fluid.

The effects on sodium balance are variable; the tendency is for retention of sodium early followed by increased excretion later in treatment accompanied by a diuresis. 
The output of 17 -ketosteroids in the urine is different with cortisone and ACTH. With the former the cortical substance is being provided exogenously and so the adrenal cortex tends to atrophy and the level of the ketosteroids is low; with ACTH the cortex is stimulated to produce more steroids and so the ketosteroid output is increased.

Both these substances have an effect on the lymphatic system. After a dose of ACTH too small to produce clinical effects there is a significant fall in the circulating eosinophils within four hours, and Thorn, et al. (1950) have concluded that this eosinophil response is a sensitive index of adrenocortical activity. Cortisone in much higher dosage produces a less striking temporary fall in eosinophils. There is also a fall in lymphocytes and a transient reticulocytosis with a rise in the erythrocyte count.

Prolonged administration of large doses of cortisone or AC'TH may produce many of the clinical features of Cushing's syndrome. These are seen as rounding of the face, the production of striae, hirsutes and acne form eruptions. These regress after the hormone is stopped. Changes of mood have occurred and acute psychoses have occasionally been reported.

With ACTH, which is prepared from animal pituitary glands, there may occasionally be minute quantities of other anterior and posterior lobe hormones. The posterior hormones may cause smooth muscle contraction giving rise to intestinal cramps. Occasional reports have appeared of pigmentation from the melanophore-expanding content.

\section{Clinical Investigations}

\section{Rheumatic Disease}

(a) Rheumatoid arthritis. Most of the work with these substances has been done in this field following the original reports of Hench, Kendall, Slocumb and Polley (1949) on their effects in rheumatoid arthritis.

Some thousands of cases have now had short periods of treatment in America, and reports of substantial series with months of treatment have come from Boland (1950), Freyberg (1950), Astwood (1950) and Hench, et al. (1950). All have confirmed the remarkable results in this disease.

The response to cortisone and ACTH in rheumatoid arthritis is usually as follows: A diminution first in stiffness and aching, then in tenderness and swelling. The response to ACTH is usually within the first 12 hours, with cortisone a little longer, up to 48 hours; complete relief of pain and often of swelling occurs during the first week. The sedimentation rate falls to normal within two or three weeks and the haemoglobin rises at a slightly slower rate.

Flexion deformities of the knees have disappeared in some cases under cortisone, and even with severe radiological change the increase in movement resulting from the aboliton of pain is often surprising. The strength of the grip will double under the influence of these drugs, and patients who could barely perform such movements as hopping or standing on their toes can do so easily, as shown by Copeman, et al. (1950).

The majority of cases relapse soon after the drugs are withdrawn, though a few cases have been reported which maintained their improvement for long periods. The main trend of research at the moment is aimed at finding the best programme for maintenance therapy. In some clinics it has been found that the full effect can be maintained by three injections a week, while in others it is felt that short courses should be given in the hope that remissions will be induced and that the intervals between treatment will allow the adrenal cortex to recover from the effects either of artificial stimulation by ACTH or of providing exogenous cortisone. Stimulus has been given to this work by the publication by Freyberg, et al. (1950) of excellent results with Merck's cortisone given orally to four patients. Good results from oral cortisone are also reported from the Mayo Clinic.

It must be made clear that in rheumatoid arthritis neither cortisone nor ACTH will reverse the bone and joint damage already produced by the disease, but while they are being given the patient appears to be protected from further damage.

(b) Rheumatic fever. Soon after the preliminary paper on rheumatoid arthritis the Mayo Clinic Group (Hench, et al., 1949) announced the early trials in rheumatic fever. The acute manifestations of this disease, fever, acute polyarthritis, tachycardia and the 'toxaemia' usually disappeared within a few days on adequate doses of these hormones. This has been followed by longer studies by Massell, et al. (1950) using ACTH, and by Barnes (1950) using both hormones. The latter concludes that cortisone and $\mathrm{ACTH}$ can suppress the acute manifestations of rheumatic fever in three weeks or less. It is considered that treatment should be planned to maintain suppression of the acute manifestations until its inherent duration is over, since it is doubtful if the course of the disease is shortened.

Cortisone and ACTH were not observed to prevent recurrence or to modify pre-existing chronic valvular damage. It will require long periods of observation to determine whether by suppression of the disease in the acute phase cardiac damage is prevented, but it is reasonable to 
hope that as the other manifestations are removed by these hormones the heart may also be protected.

(c) Ankylosing spondylitis. In America this condition is regarded as a variant of rheumatoid arthritis and so cases which have been treated have been included under that general heading. It seems that the disease responds to these hormones in the same way as rheumatoid arthritis, with relief of pain, increased movement and a fall in sedimentation rate. Again no reverse of permanent deformity occurs though increase in spinal movement and chest expansion occur when there is radiological evidence of spinal involvement. Relapse occurs when the drugs are withdrawn.

(d) Still's disease. Juvenile rheumatoid arthritis has responded in the same way as the adult form to cortisone and ACTH. The details of two cases have been reported by Elkington, et al. (1949). In most workers' experience, adequate dosage of these hormones in children depends more on the severity of the disease than on body size. For good anti-rheumatic effects as much may be needed as in an adult, but the metabolic and endocrine complications may be greater because of the larger ratio between hormone dosage and body size.

(e) Gout. Recent studies have implicated the pituitary-adrenal relationships in this disease. Wolfson, et al. (1949) observed that the urinary excretion of 17 -ketosteroids was uniformly greatly diminished in gouty patients, both during acute attacks and during asymptomatic intervals. This was not found in patients with non-gouty hyperuricaemia. This findings suggested that in gout there may be a disturbance in steroid metabolism.

Robinson, et al. (1948) found that ACTH given to normal non-gouty subjects resulted in a prompt increase in urate excretion, which reached its peak on the ninth day. This also occurred in gouty subjects with a fall in the level of the uric acid in the blood.

ACTH given during an attack of acute gouty arthritis will promptly produce relief in the acute joint symptoms, and a single dose of $50 \mathrm{mg}$. will achieve this. However the attack usually recurs in the same or other joints. It has been found by some observers that if the ACTH is followed by colchicine in normal doses for an acute episode the attack does not recur, but this is not a consistent finding.

At the moment more work is required on this problem, but there seems no doubt that gout is bound up with the pituitary-adrenocortical mechanism.

\section{Other Conditions}

(a) Addison's disease. Since the introduction of treatment with DOCA the expectation of life of patients with this condition has been considerably prolonged. However this substance does not fully replace the functional activity of the adrenal $\stackrel{\circ}{\circ}$ cortical secretions, and this is evident when the patient is ill or is subjected to any other forms of $\overrightarrow{\vec{\rho}}$ stress. There is a rational hope that cortisone will $\frac{7}{0}$ correct these deficiencies, and though it has not yet been used long enough for a full appraisal reports $\overline{\bar{\omega}}$ are beginning to appear suggesting that this hope may be fulfilled.

Thorn, et al. (1949) noted striking clinical improvement with $50 \mathrm{mg}$. cortisone daily combined with DOCA. This improvement was maintained by the use of subcutaneous implants of pellets of cortisone. Salassa (1950) has reported a patient $\overrightarrow{8}$ with Addison's disease complicated by diabetes who was maintained in excellent condition by 3 i mg. DOCA daily and $25 \mathrm{mg}$. cortisone three times a week. It therefore seems that these substances may be of value in this condition in much smaller dosage than in other diseases which are benefited.

(b) Disseminated lupus erythematosus. Baehr and Soffer (1950) reported the use of cortisone and ACTH in five patients critically ill with this disease. There was marked relief of weakness and arthralgia with a fall in temperature, subsidence of gallop rhythm and disappearance of pleuritis and pericarditis. The dose required was high and o there was immediate relapse on stopping the drugs In spite of the remarkable clinical improvement the sedimentation rates remained elevated, the leucopenia persisted and L-E cells could still be found in the sternal marrow and peripheral blood.

Brunsting, et al. (1950) reported the effects of $\mathbb{\triangle}$ cortisone in seven cases. They found a sup- $\overrightarrow{\vec{B}}$ pression of symptoms and in one case a remission $\frac{9}{3}$ lasting for a year after $x 66$ days of hormone, but $\supset$ confirmed the absence of change in the laboratory phenomena. Evidence of hypercortisonism was seen fairly frequently and three of the patients 3 died from complications of the lupus.

(c) Periarteritis nodosa. Shick, et al. (1950) have used cortisone in the treatment of four patients $ᄋ$ who were critically ill with periarteritis nodosa of some standing, and of two patients with cranial $\frac{}{5}$ arteritis. Two others with periarteritis received ACTH.

All patients experienced prompt subjective re- $N$ lief with subsidence of fever and sedimentation rate. Partial relapse occurred on withdrawal of $N$ the hormones. Two patients who were critically $\tilde{\omega}$ ill died in cardiorenal failure after initial improvement. Biopsy, studies were undertaken in these 0 cases and showed histological evidence of healing.

(d) Asthma and hay fever. Carryer, et al. (1950) have published the results of a study on 0 the influence of cortisone in bronchial asthma and $\frac{P}{\Phi}$ hay fever resulting from sensitivity to ragueed $\stackrel{D}{\circ}$ 
pollen. The degree of exposure of a patient to the offending allergen was estimated by a day to day study of the pollen content of the air. Each patient experienced prompt relief in a manner greater than previously achieved with hyposensitization or with the use of anti-histamine drugs. This relief was confined to the period during and immediately following the administration of cortisone. Astwood, et al. (1950) have used corticotrophin in status asthmaticus and severe cases of asthma with success.

(e) Ulcerative colitis. As far as can be seen these substances cause symptomatic relief with subsidence of bowel irritability, but in only a few cases has there been evidence of reversal to a normal appearance of the bowel on sigmoidoscopy. Du Toit (1950) concludes that although ACTH exerts a favourable effect it does not eradicate the disease process. Dearing and Brown (1950) report on four cases; they did not note any striking improvement.

(f) Ophthalmic diseases. There is cause for hope that cortisone and ACTH may be of value in inflammatory eye conditions, particularly those connected with the rheumatic diseases.

Olson, et al. (1950) report on seven patients with inflammatory lesions of the cornea and uveal tract. Striking benefit was obtained in all of the patients. Pain and photophobia were relieved in all cases within four hours. Two patients with acute plastic iritis are considered to be cured. In a later report these workers report good results from topical applications.

Henderson and Hollenhorst (I950) report on six cases in four of which the eye condition was associated with rheumatoid arthritis, and both ophthalmic and joint condition improved. In one case where an intra-ocular operation was performed for relief of glaucoma during the course of uveitis, cortisone kept the inflammation under control so that no harm resulted from the surgical procedure.

\section{Dosage}

Perhaps it was a stroke of genius that led Hench in the first clinical trial of cortisone to use doses which, up to then, would have been considered excessive for hormone therapy. If he had not done so he might have missed the effect entirely, for neither of these hormones have any effect unless given in large doses at the onset. With cortisone the initial dosage should be $300 \mathrm{mg}$. the first day, $200 \mathrm{mg}$. the second day and then $100 \mathrm{mg}$. daily. With ACTH 60 to $100 \mathrm{mg}$. per diem must be given at the beginning. This drug is very quickly eliminated from the body so ro or I $5 \mathrm{mg}$. must be given six hourly by injection.
These initial doses have been established over a large number of trials in cases of rheumatic disease, and have been applied also to other conditions. Where only a short period of treatment is necessary, as in status asthmaticus or inflammatory eye lesions, there is little likelihood of overdosage with metabolic or endocrine consequences. However, where treatment has to be given for long periods in the more chronic group, such as rheumatoid arthritis, it has been found feasible to lower the dosage once a full therapeutic effect has been achieved.

The optimum scheme for maintenance dosage is still the subject of research and each centre in America has a slightly different method. In some the intervals between doses are lengthened so that patients are receiving $100 \mathrm{mg}$. cortisone three times a week, and in others the drug is given in definite courses lasting a few weeks at a time.

Because of the rapid elimination of ACTH the emphasis has been more on the lowering of dosage; and patients are being taught to give themselves injections of small amounts, perhaps a total of only ro mg. per diem, in divided doses. Boland (1950) has reported that 36 of 42 patients with rheumatoid arthritis were successfully treated for long periods with a maintenance dosage of between $32 \mathrm{mg}$. and $65 \mathrm{mg}$. per diem.

\section{Precautions}

In the early days of research on these hormones alarming reports were circulated about the undesirable effects produced by them. With further study a more rational outlook is being taken, and as Hench (1950) says, "They are now features to be respected but not to be feared.'

However, as in the case of other powerful therapeutic agents having potentially harmful effects, the physician must weigh carefully the advantages of treatment with cortisone or ACTH against their possible deleterious effects.

(a) Psychic changes. While definite improvement in the mental attitude of patients usually occurs with these hormones, there may be an exaggerated sense of well being. In the chronic diseases such as rheumatoid arthritis the dramatic relief from pain and disability results in a return of self confidence, of an optimistic elated mood with an acceleration of the tempo of thinking and physical activity.

Rome and Braceland (1950) have observed the large series of patients with various conditions being treated with cortisone at the Mayo Clinic. They divide psychiatric responses into four groups:-

I. Those who express their, relief from being 
free from pain in a rejuvenated hope of normal life.

2. Those who show with this relief, together with an elaboration of stimulation and some degree of exhibitionism.

3. Those who have a history of previous psychological conflict and had experienced mitd hypomania or mild depression or both. In this group previous personality conflicts may be exacerbated by the hormones, and they may develop phobias or ritualistic behaviour.

4. A small group composed of patients with a prepsychotic personality. Short periods of psychosis have been seen in some of these.

It is therefore extremely important that a careful psychiatric evaluation of the patient's personality and family history should be carried out where the use of these hormones is contemplated. Mental changes do not persist if the drugs are stopped promptly.

(b) Sodium and water retention. These occur fairly commonly with high dosage in prolonged treatment. They can be detected by watching for a rapid gain in weight or for the presence of oedema which occurs most commonly in the feet or pre-tibial region, but has been seen as hepatic or pulmonary congestion. Often the condition rectifies itself, for when the sodium has been retained for a short time there may be a sharp diuresis, but it is usually possible to avert these difficulties by maintaining sodium chloride intake at less than a gramme daily.

(c) Hypokalaemia. High dosage of both these hormones may cause increased urinary excretion of potassium with the production of metabolic alkalosis. Generalized weakness and occasionally hiccough are symptoms which occur, and signs of this condition appear as hypotension, depression of $\mathrm{T}$ waves, $\mathrm{S}-\mathrm{T}$ segment and $\mathrm{S}-\mathrm{T}$ junction in the electrocardiogram and increase in the $\mathrm{CO}_{2}$ combining power. If this complication occurs potassium must be given either as the chloride or nitrate and the dosage of the hormone reduced.

(d) Hyperglycaemia. Increase in blood sugar and impaired glucose tolerance have been observed in non-diabetic patients during administration of cortisone and ACTH. Most observers'now agree that this only occurs in pre-diabetics and in patients with a diabetic family history. It is wise to do a carbohydrate tolerance curve before starting treatment. If glycosuria appears the dosage should be reduced, unless this is impracticable, when it can be controlled with insulin.

(e) Cushing-like changes. Watch must be kept for excessive rounding of the face, striae on the buttocks or abdomen, hirsutes and acne form eruptions. At the first sign of these the dosage must be reduced drastically.

\section{Summary}

There are several differences between cortisone and ACTH which must be noted. The absorption and distribution of ACTH is rapid, and so it must be given three or four times a day at first. Armour Ltd., the makers, have announced the production of a long-acting vehicle which may obviate this difficulty. Cortisone acetate is absorbed more slowly and one daily injection usually suffices. ACTH being a protein may produce foreign protein reactions, and may contain minute amounts of posterior pituitary hormone, causing involuntary muscle contraction in the bowel or bladder; with cortisone, which is a crystalline substance, there are no such reactions.

The two substances are not of equal potency and $40 \mathrm{mg}$. ACTH is comparable with $100 \mathrm{mg}$. cortisone. The production of both substances has been increased, although there is as yet no news of the synthesis of either, but steps in the partial synthesis of cortisone and in the extraction of ACTH have been improved and made less costly, so that the price has fallen rapidly in the last yearo They are each now available in limited quantities to all approved American hospitals, and it is hope that with growing production supplies will soon be available to medical centres outside North America.

The psychological effects of these drugs appear to be non-specific, though in their ability to affect the symptom-complex of certain diseases ther appear to be group specific. They do not act bykilling germs or removing toxins but seem to act as a shield between the irritant and the patient while they are being given. As Dr. Hench put it recently, "They do not extinguish the fire nor repair the damage, but provide an asbestos suit which protects the patient. As long as the protection is not discarded until the end of the natural duration of the disease, the patient remains well.'

In spite of an enormous amount of research in the States during the last 18 months there is as yet no knowledge as to exactly how these substances provide this protection. It is considered that they act at the tissue level but neither the exact site or method has been discovered. It is clear that in these two hormones we have a new and potent therapeutic weapon. Much work still remains to be done before we know the best method of using them. In addition new vistas for investigation have been revealed in a field of chronic diseases which has previously baffled research workers. 


\section{BIBLIOGRAPHY}

ASTWOOD, E. B., CLEROUX, A. P., PAYNE, R. W., and RABEN, M. S. (1950), Bull. New Eng. Med. Center, 12, 2. BAEHR, G., and SOFFER, L. J. (1950), Bull. New York Acad. Med., 26, 229.

BARNES, A. R. (1950), Proc. Staff Meet. Mayo Clin., 25, 478.

BOLAND, E. W., and HEADLEY, N. E. (1949), f. Amer. Med. Ass., 141, 301.

BOLAND, E. W., and HEADLEY, N. E. (1950), Ibid., 144, 365.

BOLAND, E. W. (1950), Ann. Rheum. Dis., 91,

BRITTON, S. W. (1930), Physiol. Rev., 10, 617.

BROWN-SEQUARD (1856), C.R. Acad. Sci., 43, 422, 542.

BRUNSTING, L. A., SLOCUMB, C. H., and DIDCOCT, J. W (1950), Proc. Staff Meet. Mayo Clin., 25, 479.

CARRYER, H. M., KOELSCHE, G. A., PRICKMAN, L. E. MAY'TON, C.' K., LAKE, C. F., and WILLIAMS, A. L. (1950), Ibid., 25, 482 .

COPEMAN, W. D. C., SAVAGE, O., BISHOP, P. M. F., DODDS, E. C., GOTTLIEB, B., GLYN, J. H. H., and KELLIE,' A. E.' (1950), Brit. Med. Ұ̧our., 849.

DEARING, W. H., and BROWN, P. W. (1950), Proc. Staff Meet. Mayo Clin., 25, 486.

DOUGHERTY, T. F., and WHITE, A. (1943), Proc. Soc. Exp. Biol. N.Y., 53,132 .

DU TOIT, C. H. (1950), Prog. 42, Ann. Meet. Am. Soc. Clin. Invest., 19.

ELKINGTON, J. R., HUNT, A. B., GODFREY, L., MCCRORY, W. W., ROGERSON, A. G., and STOKES, J. (1949), F.A.M.A., 141, 1273 .

EVANS, H. M. (1924), Harvey Lectures, 19, 212.

FREYBERG, R. H. (1950), Bull. N.Y. Acad. Med., 26, 206.

FREYBERG, R. H., TRAEGER, C. T., ADAMS, C. H., KUSCHU, T., WAINERDI, H., and BONOMO, I. (1950), Science, 112, 429.

de GROOT, J., and HARRIS, G. W. (1950), F. Physiol., III, 12.

HARTMAN, F. A., BROWNELL, K. A., and HARTMAN, W. E. (1930), Am. F. Physiol., 95, 670.

HENCH, P. S., KENDALL, E. C., SLOCUMB, C. H., and POLLEY, H. F. (1949), Proc. Mayo Clin., 24, I8I.

HENCH, P. S., KENDALL, E. C., SLOCUMB, C. H., and POLLEY, ̈̈. F. (1950), Archives Int. Med., 85, 545.

HENCH, P. S., SLOCUMB, C. H., BARNES, A. R., SMITH, H. L., POĹLEY, H. F., and KENDALL, E. C. (1949), Proc. Mayo' Clin., 24, 277.

HENCH, P. S. (1950), Proc. Roy. Soc. Med., 43, 10, 769.

HENDERSON, J. W., and HOLLENHORST, R. W. (1950), Proc. Staff'Meet. Mayo Clin., 25, 490.
HENLy, A. A. (1949), Ann. Rept. Dept. Rheum. Dis., West Lond. Hosp., 18.

LI, C. H., SIMPSON, M. E., and EVANS, H. M. (1942), Science, 96, 450 .

LI, C. H., SIMPSON, M. E., and EVANS, H. M. (1943), F. Biol. Chem., 1949, 413.

LI, C. H. (ooo), First Internat. Cong. Biochem. Abs. of Communications, 386.

MASSELL, B, F WASSEN, J, E. STURGIS, G. P., HALL, B., and CRAIG, E. (1950), Nerc Eng. F. Med., 242, 641.

OLSON, J. A., STEFFENSEN, E. H., MARGULIS, R. R., SMITH, R. W., and WHITNEY, E. L. (1950), 手.A.M.A., $142,1276$.

OLSON, J. A., STEFFENSEN, E. H., MARGULIS, R. R., SMİTH, R. W., and WHITNEY, E. L. (1950), Am. F. Ophth., 33, 1033 .

PFIFFNER, J. J. (1942), Advances in Enzymology, 2, 325.

POLLEY, H. F., and MASON, H. L. (1950), f. Amer. Med. Ass., 143, 1474 .

ROBINSON, W. D. COUN, J, W. BLOCK, W. D., and LOUIS, L. H. (1948), f. Lab. Clin. Med., 33, 1473.

ROGOFF, J. M., and STEWART, G. N. (1926), Amer. Four. Physiol., 78, 711 .

ROME, H. P., and BRACELAND, F. J. (1950), Proc. Staff Meet. Mayo Clin., 25, 495.

SALASSA, R. M. (1950), Ibid., 25, 497.

SARETT, L. H. (1946), f. Biol. Chem., 162, 601.

SAYERS, G., SAYERS, M. A., WHITE, A., and LONG, C. N. H. (1943), Proc. Soc. Expt. Biol. N. Y., 52, 199.

SHICK, R. M. BAGGENSTOSS, A. H., FULLER B. F., and POLLEY, H. F. (1950), Proc. Staff Meet. Mayo Clin., 25, 492.

SPRAGUE, R. G., MARSCHELLE H. P., MASON, H. L., ALBERT, A." MATHIESON, D. R., HENCH, P. S.; (1950), Arch. Int. Med., 85, 199.

STEWART, G. N. (1924), Physiol. Rev., 4, 163.

STIEGER, M., and REICHSTEIN, T. (1937), Helv. Chim. Acta., 20, 1164 .

SWINGLE, W. W., and PFIFFNER, J. J. (1930), Science, 71, 32t. SWINGLE, W. W., PFIFFNER, J. J. (1929), Anat. Rec., 44 225. THORN, G. W., FORSHAM, P. H., BENNETH, L. L., ROCHE, M. REISS, R. S., SLESSOR, A., FLUIK, E. B., and

THORN, G. W., FORSHAM, P. H., FRAWLEY, T. F., HILL S. R., ROCHE, M. STAEHELIN, D., and WILSON, D. L. (1950), New Eng. Y. Med., 242, 783.

WOLFSON, W. Q., GUTERMAN, H. S., LEVINE, R., COHN, C., HUNT, H.' D., and ROSENBERG, E. F. (1949), $¥$. Clin. Endocrinol., 9, 497.

\section{RUTHIN CASTLE, NORTH WALES}

A Clinic for the diagnosis and treatment of Internal Diseases (except Mental or Infectious Diseases). The

Clinic is provided with a staff of doctors, technicians and nurses.

The surroundings are beautiful. The climate is mild. There is central heating throughout. The annual rainfall is $\mathbf{3 0 . 5}$ inches, that is, less than the average for England.

The Fees are inclusive and vary according to the room occupied.

For particulars apply to THE SECRETARY, Ruthin Castle, North Wales.

Telegrams : Castle, Ruthin.

Telephone: Ruchin \&S. 